\title{
PROSPECT STRONGHOLD
}

\section{Owen Nichols}

Arquitecto, Chibbernoonie Nueva Jersey, EE.uU.
Sissily Harrell

\author{
Arquitecta, Chibbernoonie
} Nueva Jersey, EE.uU.

How to transform an element such as ordinary as a fence into an exceptional operation? After that question, this project detaches from the generic solution -that which is available in the market- to analyze, rethink and design a fence considering all of its dimensions, from its status of an item that solves a practical problem to its cultural and architectural effects.

KEYWORDS - fence, commodity, suburb, residential, defense

The status quo begins as an outlier. It is imbued with a critical degree of intelligence in the first stages of conception. An architectural element is manifest from a direct need to inform space, yet when the functionality that results occludes its very ability to embody an idea or have a spatial effect, that element becomes a commodity.

A fence is one of these commodified building elements. It keeps the neighbor at bay, finding form in a nondescript line of vertical posts and horizontal ties that mark the property line. This fence is also a symbol. The 'white pickets' conjure the American Dream, protecting, containing, perhaps even obscuring the house, the dog, the car, the kids, the yard. Yet, these nondescript lines are so ubiquitous that they become invisible within the residential landscape.

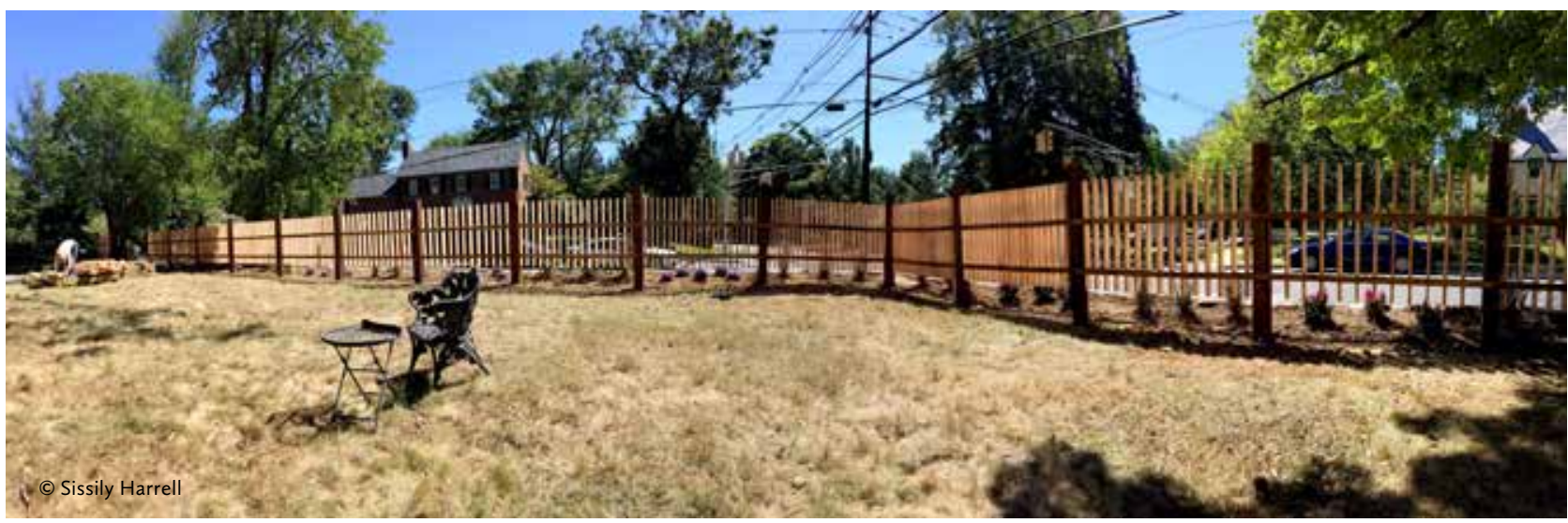




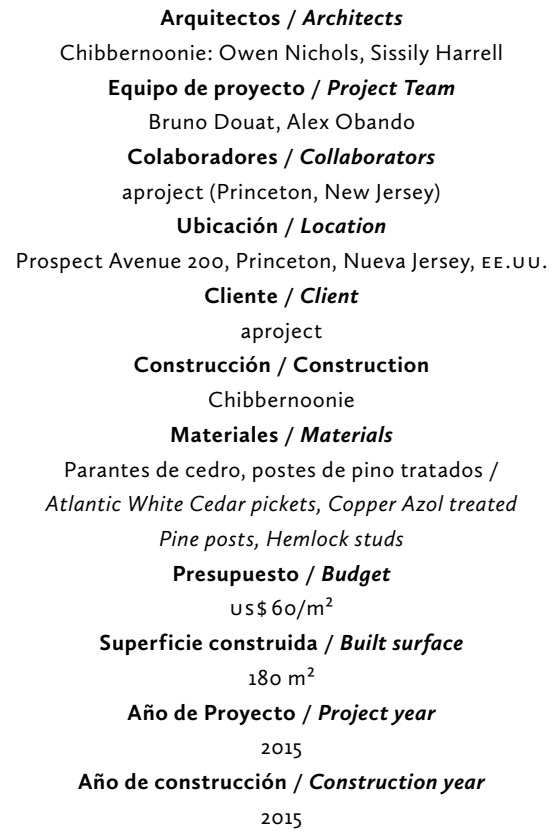

\section{CHIBBERNOONIE}

Founded in 2015 by Owen Nichols and Sissily Harrell, Chibbernoonie is an art and architecture collaborative that engages handmade narratives, age-old visual theory, and unequivocal visceral prompts to generate various lenses through which to explore design.

\section{SISSILY HARRELL}

<sissily@chibbernoonie.com>

Master in Architecture, GSAPP, Columbia University, New York, 2015. Bachelor of Science in Architecture, University of Virginia, 2006. Architectural Designer and Co-founder, Chibbernoonie 2015.

\section{OWEN NICHOLS}

<owen@chibbernoonie.com>

Master in Architecture, GSAPP Columbia University, New York, 2013. Bachelor of Fine Arts, Drawing and Printmaking, Montclair University, New Jersey, 2008. Architectural Designer and Co-founder, Chibbernoonie 2015. Professor at Parsons The New School for Design and Columbia University.
Planta de emplazamiento /

Site plan

E. / S. 1:500

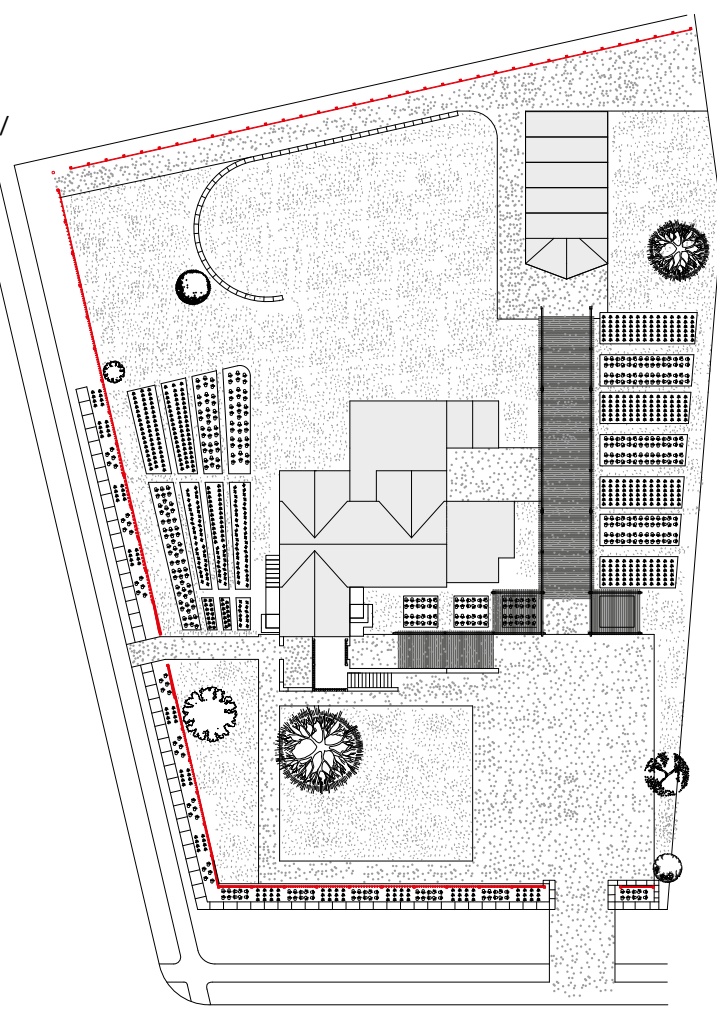

Diagrama de visibilidad de la cerca,

según diferentes ángulos / Fence parallax diagram

E. / S. 1:50 (aprox.)
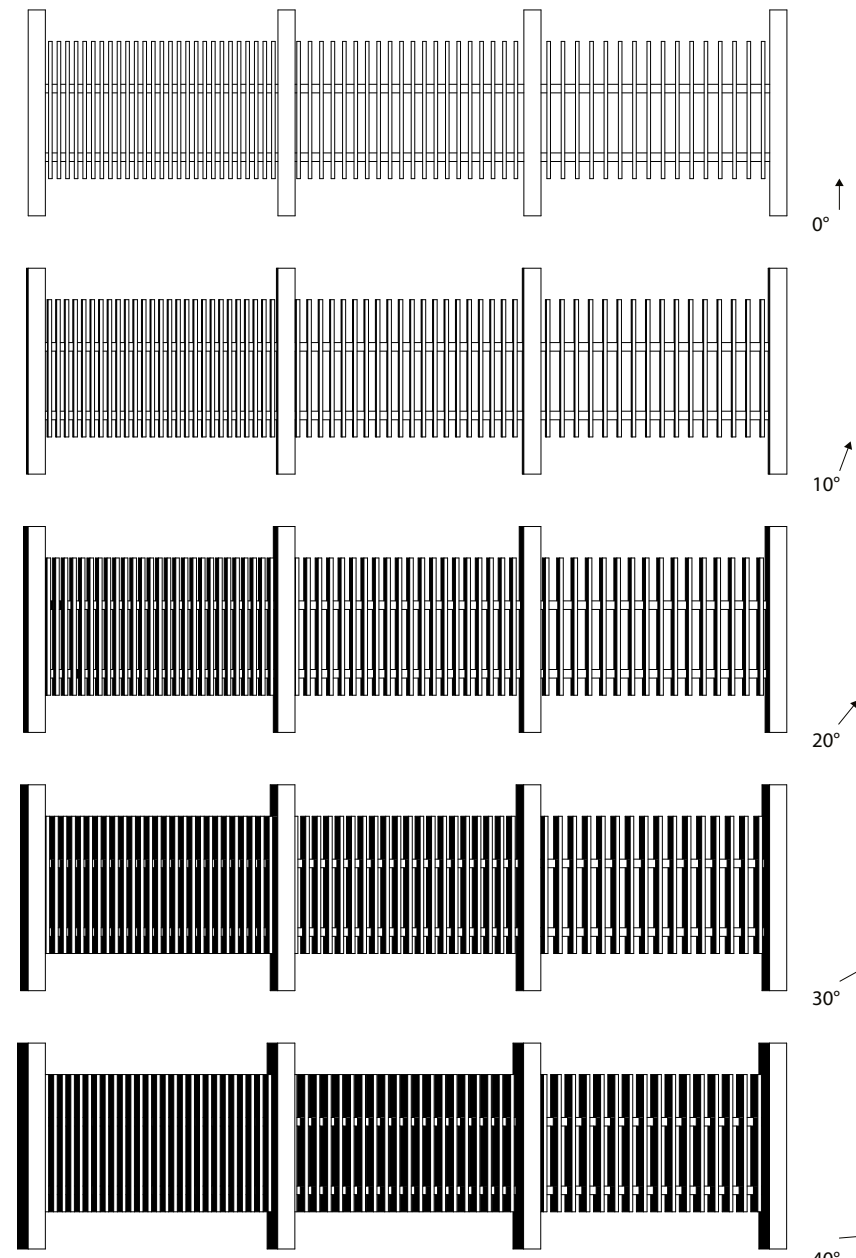
Diseños de cercas residenciales comunes /

Common fence design profile

S. E. / N.S.
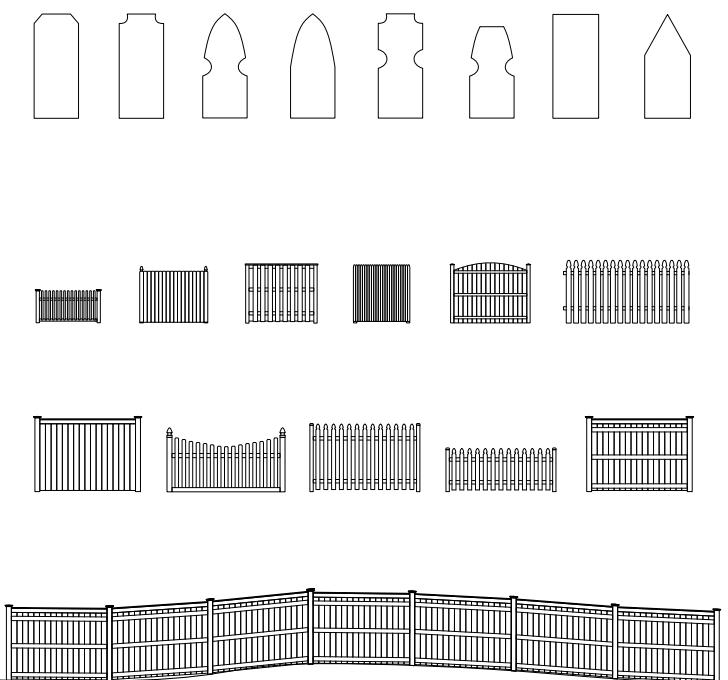

†

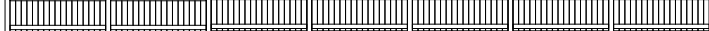

Isométrica despiece cerca /

Fence exploded axonometric

S. E. / N. S.

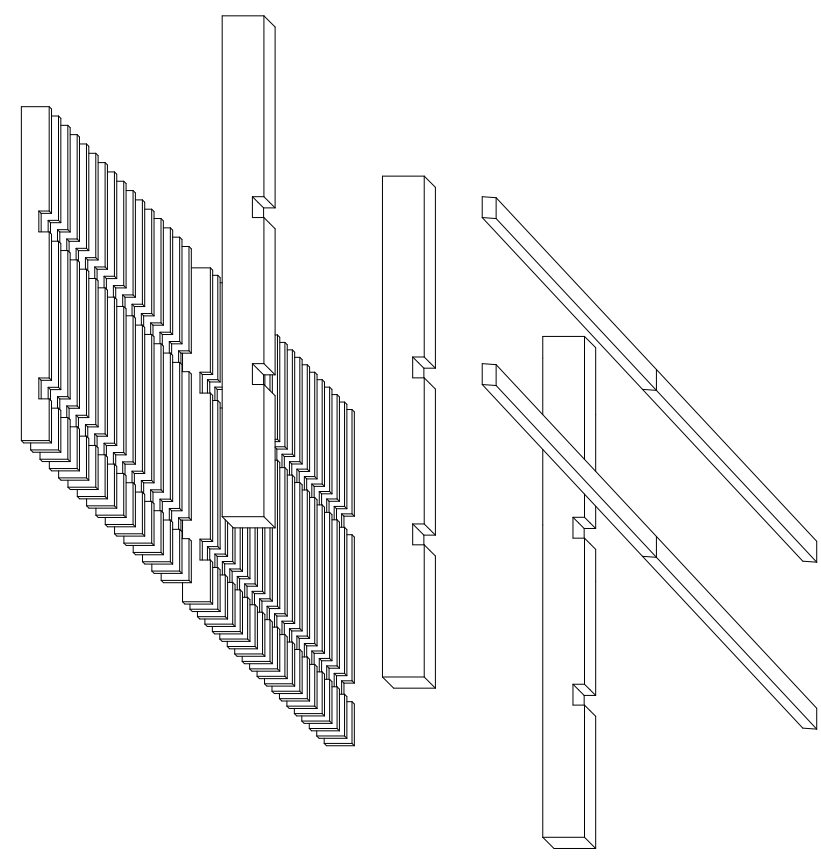

The project for a dynamic picket fence usurps this accepted, now commodified, condition: Prospect Stronghold is a defensive residential landscape reinforcing a house's right to secure itself against the wandering eye of its neighbors and strange passers-by.

Prior to the construction of the Stronghold, the large, open area surrounding the house was given over by the public domain. The fence reclaims this zone for the house by simply enclosing the yard.

The Stronghold dictates variations in visibility along its length by creating a protective screen on the corner lot. The white cedar fence on the outer-most boundary of the complex is composed of thin, vertical pickets whose depth and rhythm in spacing is calibrated to limit (sneaky) oblique visibility where desired.

The Stronghold enlists its structure in a strategy of disruptive layering and camouflage that captures the eye and diverts it from the house. It employs tactics of a wall to reclaim the territory of the house, enclosing yard and garden, while negotiating the terms of essential use between house and street.

For there to be an extraordinary condition, there must be an accepted order to which it inherently refers. Such an exception defies, eludes, transcends. The Prospect Stronghold takes this challenge to go far beyond its neighbors' banal form and call to basic function, to once again represent beauty and power in the residential landscape. ARQ 
Corte transversal, acera-cerca-patio

Cross section, street-fence-yard

E. / S. 1:50 (aprox.)

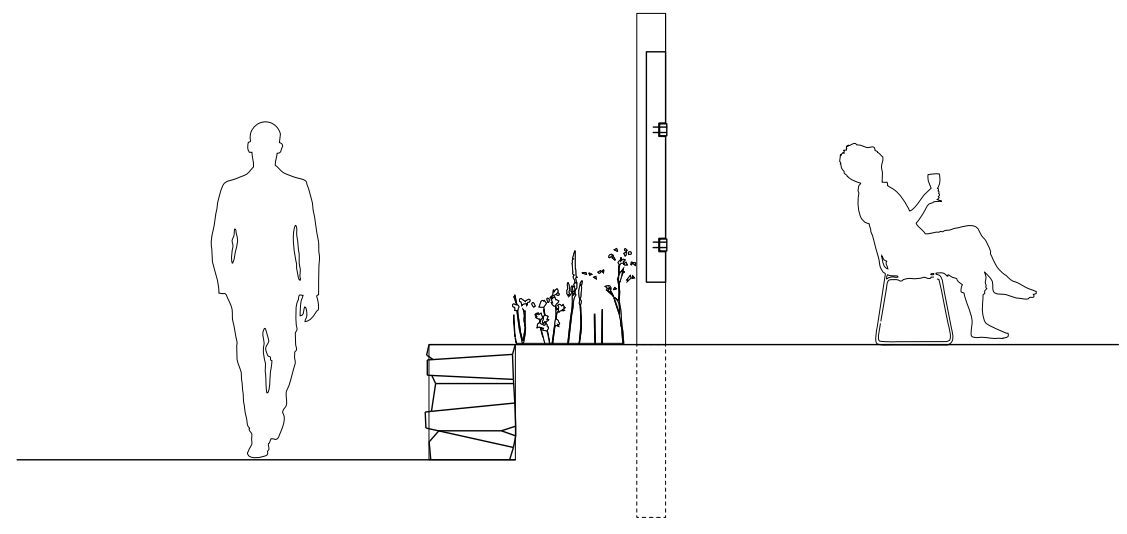

Perspectiva / Perspective

S. E. / N.S.
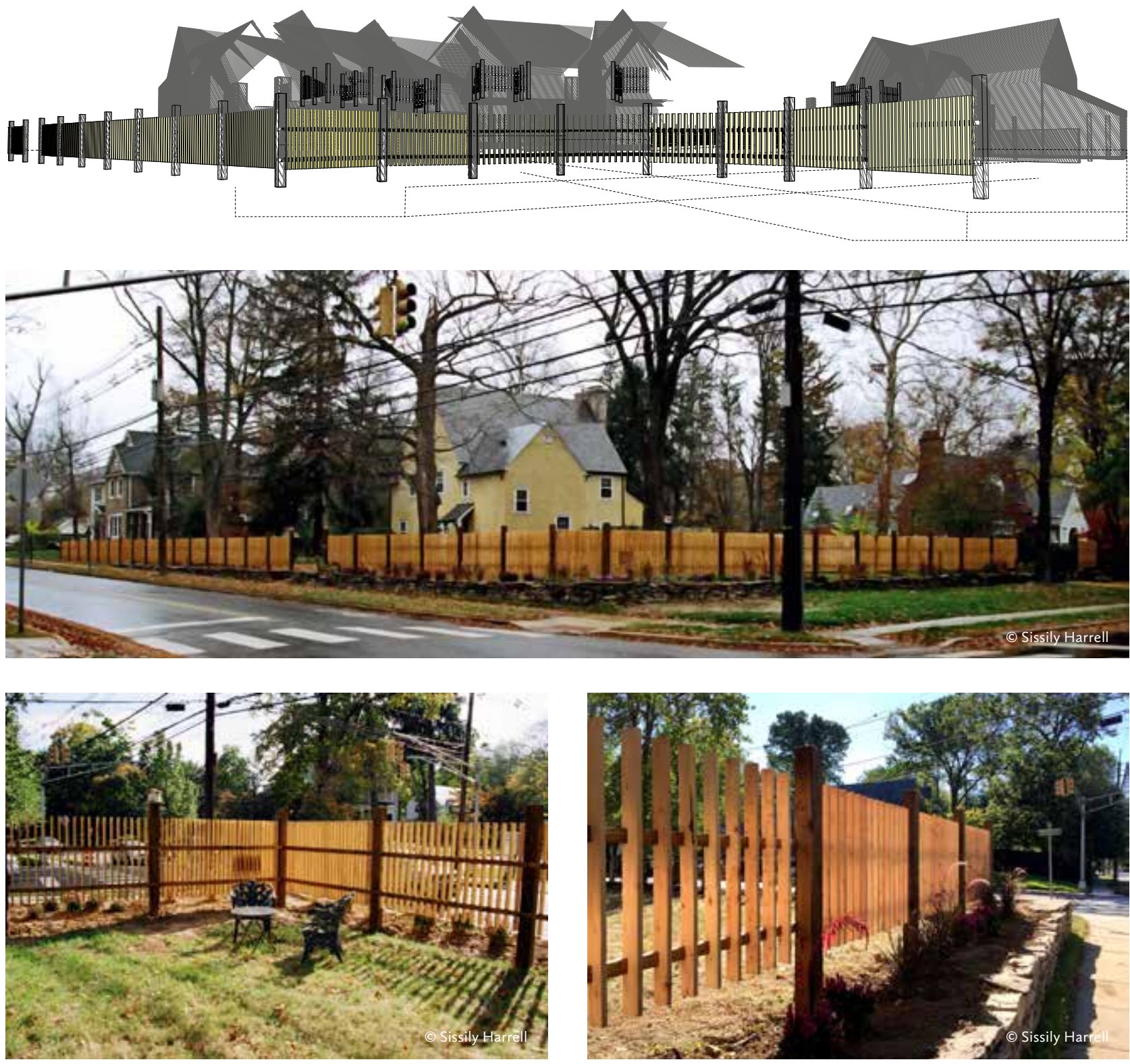